\title{
Derechos fundamentales y vía pública
}

\author{
Lorenzo Martín-Retortillo Baquer \\ Catedrático de Derecho Administrativo
}

\begin{abstract}
SUMARIO: I. FUNGIONALIDAD DE LOS DERECHOS FUNDAMENTALES. II. LA GALLE Y SU REGULACIÓN JURÍDICA. III. LÍMITES A LOS DERECHOS FUNDAMENTALES, EN ESPECIAL, EL RESPETO A LOS DERECHOS DE LOS DEMÁS. A. Doble faz del derecho de manifestación. B. Algunas peculiares ocupaciones irregulares de las vías públicas. C. La prohibición de circular con la cara cubierta. IV. A MODO DE CONGLUSIÓN.
\end{abstract}

RESUMEN: Las vías públicas son el escenario habitual de una serie de derechos fundamentales, como el de libre circulación, el de manifestación, también, a veces, el de libertad de expresión o el de libertad religiosa. De ahí que se imponga un régimen jurídico para que el ejercicio del derecho de unos no impida el de los demás y, en todo caso, proporcionando reglas para solventar los posibles litigios. La consideración de las vías públicas como una propiedad del municipio, con el minucioso régimen de utilización de las mismas, sirve en gran medida para asegurar esos fines, sin olvidar que, al margen de la propiedad, hay que tener en cuenta la competencia de otras Administraciones encargadas del mantenimiento de la seguridad.

PALABRAS CLAVE: Derecho de manifestación, derechos fundamentales, las calles como propiedad municipal, límites de los derechos fundamentales, ocupación irregular de la calle, respeto a los derechos de los demás, vías públicas.

ABSTRACT: Very important freedoms and human rights, like freedom of movement, freedom of public assembly and, sometimes, freedom of speech or of religion, take place in the street. So, legal rules are necessary to protect their practice, to protect the rights and freedoms of others and to avoid disputing factions.

KEY WORDS: Every right has its limitations, freedom of demonstration, human rights, illegal occupation of streets, the protection of the rights and freedom of others, the public streets belong to the municipality.

La vida que transcurre en la calle ocupa un lugar muy destacado en nuestro modelo de sociedad. Espacio vivo para la convivencia, para lo lúdico y lo festivo y las celebraciones, o para la solidaridad y la tristeza, para el trabajo o el mercado, o para el 
simple tránsito, reclama por fuerza unas reglas, aunque sólo sea para administrar "un bien escaso". La perspectiva de los derechos fundamentales, contando con el punto de partida de la profunda proclamación de la libertad, ofrece criterios válidos para garantizar la opción de la convivencia.

\section{FUNCIONALIDAD DE LOS DERECHOS FUNDAMENTALES}

1. Habrá que arrancar, para comenzar, de un punto de partida elemental, y es que no todo vale para todos los tiempos y circunstancias. No cabe generalizar frívolamente: el argumento que se va a desarrollar se sitúa en un clima en el que la organización del Estado y sus relaciones con los ciudadanos están presididos por la libertad como valor esencial. Como se dice en el Preámbulo de la Constitución de 1978, "La Nación española deseando establecer (...) la libertad (...) y promover el bien de cuantos la integran”, debiéndose precisar que ya el artículo primero propugna entre los valores superiores del ordenamiento jurídico, la libertad.

En el otro gran núcleo en que estamos insertos, la Unión Europea, el artículo 2 del Tratado de la Unión Europea, recalca que "la Unión se fundamenta en los valores de respeto de la dignidad humana, (...) libertad y respeto de los derechos humanos (...).

Por su parte, el Convenio Europeo de Derechos Humanos, ya en su Preámbulo, por aludir a una tercera fuente que nos preside, recalcará igualmente el patrimonio común de respeto a la libertad y a la preeminencia del Derecho.

Todo ello, entiéndase bien, desde la idea de la libertad de los modernos, por recordar la certera fórmula de Benjamín Constant, y es que como asevera el Preámbulo de la vigente Constitución, se trata de "promover el bien de cuantos la integran". Ya no estamos ante las primitivas declaraciones de derechos pensadas para favorecer a un grupo, a unas familias o a un sector concreto, sino que hoy se postula una vocación de universalidad.

2. Además, pasó el tiempo en que las declaraciones de derechos se concebían como un mero programa, o propuesta inspiradora para cuando se considerara conveniente desarrollarlos. Hoy es una de las afirmaciones paradigmáticas del Tribunal Europeo de Derechos Humanos que lo que el Convenio Europeo de Derechos Humanos, hecho en Roma el 4 de noviembre de 1950 (citado en adelante como "el Convenio" o, simplemente, CEDH), garantiza son "derechos reales y efectivos". Es decir, que no vale con menciones, o con un mero aparato normativo, sino que lo que se exige es que los derechos sean inequívocamente aplicados: "Proteger a todos los españoles (...)-dirá, en efecto, el Preámbulo de la Constitución- en el ejercicio de los derechos humanos". Y bien claramente lo consagra el Preámbulo del CEDH cuan- 
do afirma "que esta declaración tiende a asegurar el reconocimiento y la aplicación universales y efectivos de los derechos en ella enunciados", para lo cual el sistema se articula - no se olvide-, estableciendo un Tribunal garantizador. Tal exigencia de efectividad va a constituir un reto mayúsculo para los poderes públicos, que habrán de ajustar sus políticas y adoptar todos los instrumentos jurídicos necesarios para que ello suceda. Lo que se traduce, ante todo, en una postura activa, pero que implicará, no menos, un sometimiento a control: los ciudadanos habrán de contar con un recurso judicial efectivo para poder defenderse de cualquier violación de sus derechos.

3. El "favor libertatis" habrá de actuar como soplo inspirador de todo el sistema, pero no se puede olvidar que los derechos fundamentales no son valores absolutos: cada uno ha de funcionar dentro de su confin, y todos tienen unos límites que respetar. Y es que nos toca vivir en una sociedad que aspira a la convivencia. De ahí que cobre importancia en la teoría de los derechos fundamentales el posible roce y enfrentamiento entre algunos de ellos, valga la cita, por recordar el ejemplo clásico, de cómo el derecho al buen nombre o el derecho a la propia imagen, choca no pocas veces con la libertad de expresión. Aunque, al mismo tiempo, resulta también decisiva en dicha teoría de los derechos fundamentales la idea de respeto a los demás. Es decir, siempre presente la consideración de "el otro": idea firme y de origen clásico que no se toleraría que no estuviera bien arraigada. La explicaba paladinamente el artículo 4 de la Declaración de Derechos del Hombre y del Ciudadano de 1789, el texto revolucionario que, no se olvide, sigue formando parte en Francia -y personalmente entiendo que también en la Unión Europea-, del bloque de la constitucionalidad, cuando afirmaba que "La libertad consiste en poder hacer todo lo que no dañe a otro. Así, el ejercicio de los derechos naturales de cada hombre no tiene otros límites que los que aseguran a los demás miembros de la sociedad el disfrute de estos mismos derechos. Estos límites sólo pueden ser establecidos por la ley". Idea elemental, absolutamente imprescindible, que bien la recalca la Constitución española cuando en ese precepto decisivo que abre el título primero, sobre los derechos y libertades fundamentales, el artículo 10.1, incluye "el respeto (...) a los derechos de los demás", entre lo que constituye "el fundamento del orden político y de la paz social".

De una u otra manera, la idea de los límites irá apareciendo de modo expreso al momento de regularse los más cualificado derechos fundamentales y libertades públicas. Ejemplo típico sería el artículo 20.4 de la Constitución al regular la libertad de expresión - con tónica bien diferente a la del constitucionalismo estadounidense-, o, en el sistema del CEDH, la estructura de los artículos 8 a 11, referentes, respectivamente, al respeto a la vida privada, la libertad de conciencia, la libertad de expresión y la libertad de asociación y reunión, dotados todos ellos de un apartado segundo admitiendo expresamente límites o injerencias, siempre presente el "respeto a los derechos de terceros", si bien se alude también a otros límites como el orden público, la seguridad, la protección de la salud, etc. 
4. Hay una suerte de predeterminación territorial del espacio en relación con los derechos fundamentales. Ejemplo típico sería la intimidad, que clama por la reserva y la clausura, en principio, en esa zona acotada que es el domicilio. Aunque también se producen mutaciones con el cambio de usos, hábitos y, de manera especial, con las innovaciones tecnológicas, es decir, el fruto de los nuevos tiempos: el teléfono era testimonio directo de esa intimidad, inevitablemente reconducido hasta hace poco al domicilio - o a la centralita, o a la cabina-, a lo que se añadiría luego internet, con esos enormes aparatos que no había quien los moviera de casa, mientras que ahora, tanto uno como otro, se pueden utilizar con toda normalidad en la calle -o, dando la tabarra al vecino de asiento en el tren-, a través de esa enorme variedad de medios instrumentales que no cesan de simplificarse y multiplicarse, cada vez más manejables y llevaderos. Por cierto que ambos, en la medida en que no coincidan, símbolo, al menos en apariencia, del tradicional respeto a la intimidad y a la reserva, hoy bien nos consta lo amenazados que están, con una escandalosa depreciación del derecho a la intimidad, con la presencia de tantos profesionales o aficionados que juegan a las interferencias, o los organismos oficiales que expresamente se dedican a ello, no digamos si la placentera comunicación, aún sobre el asunto más trivial y cotidiano, no es interferida desde Oklahoma, por algún servicio especializado que intente descubrir infiltrados.

Buen número de derechos fundamentales, en cambio, tienen vocación directa de ejercicio en la calle. Hoy, que estamos tan preocupados e interesados por la transparencia, resulta aleccionador recordar aquellas lejanas circunstancias - tan mitificadas, por otra parte-, en que importantes decisiones políticas se tomaban al aire libre y con participación abierta, evocando el ejemplo de "el ágora" en la vieja Atenas, o de "el Foro" en la Roma clásica, o, incluso, en la España tradicional, esos supuestos tan pintorescos de "concejo abierto", en el atrio de la iglesia, o bajo la sombra protectora de algún árbol venerable ${ }^{1}$.

Hoy siguen transcurriendo al aire libre importantes testimonios de la actividad política, valga el ejemplo de tantos mítines, fiestas de partido, o la vertiente política del derecho de manifestación, que tanta relevancia adquieren en nuestros días. Aunque, obviamente, la calle como espacio para el ejercicio de derechos y libertades no se circunscribe a los de alcance político.

${ }^{1}$ Véase Enrique ORDUÑa REBOLLO, Democracia directa municipal y concejos y cabildos abiertos, Civitas, Madrid, 1994. 
5. Ordenando un poco las ideas, diré, ante todo, que hay un ramillete de derechos que, en principio, se ejercitan en el interior de edificios o instalaciones. Valgan los siguientes ejemplos.

- El derecho a la tutela judicial efectiva (artículo 24 de la Constitución), salvo el caso paradigmático, y ciertamente excepcional del Tribunal de las Aguas de Valencia - $\mathrm{u}$ otros supuestos similares-, residenciado en la puerta de la catedral, se desenvuelve como regla, descontando algunas modalidades de actividad probatoria, en los espacios judiciales.

- Supuesto típico será el derecho al domicilio (artículo 18.2), que se identifica con ese tradicional reducto, con severas reglas antes de permitir la entrada o penetración, apareciendo la exigencia de autorización judicial, el delito de allanamiento de morada, etc. Si bien recientemente, nuevos usos o nuevas invenciones, evidencian que hay agentes exteriores que pueden dañar severamente el sacrosanto reducto del domicilio, con una peculiar forma de penetración, que no es la tradicional de las personas físicas. Aparece así el rico filón de las vecindades industriales -humos, vapores, vibraciones, olores, etc.- y, últimamente, a consecuencia a la par de las nuevas concepciones del ocio y de lo festivo, así como de la generalizada falta de respeto y de educación, cada vez estará más presente en nuestros pueblos y ciudades esa plaga del ruido, de tan nocivos efectos en la vida cotidiana, y que tantos ayuntamientos se resisten a controlar, en no pocas ocasiones con la idea de favorecer a ciertos establecimientos aun en detrimento de la ciudadanía.

- En general, la intimidad personal y familiar (artículo 18.1) parece que clama por el cerrado. Pero no faltarán excepciones. Pensemos en la intimidad de una persona ensimismada en un recoleto banco del parque, ante el mar o a la vista de un paisaje o de una montaña. Dígase lo mismo de la intimidad de las efusiones de una pareja en el recodo tranquilo de un jardín. Aparte de que bajo el "respeto a la vida privada", del artículo 8 del Convenio Europeo de Derechos Humanos, el Tribunal de Estrasburgo ha deducido numerosas opciones de trascendencia en el espacio público, como por ejemplo, decantarse con la llevanza de determinadas vestimentas.

- En fin, clara vocación de desarrollo en espacios cerrados, en principio, se manifiesta, entre otros, con el derecho de asociación (artículo 22), fundación (artículo 34), acceso a los cargos públicos (artículo 23.2), sindicación (artículo 28) y petición (artículo 29), sin perjuicio de que algunos de ellos, en determinadas circunstancias, busquen una clara proyección exterior: llevar personalmente en grupo una petición, pretensión que se traduce en una manifestación o, incluso en una huelga, etc.

6. En cambio, casi por definición, ofrecen una clara vocación de presencia exterior no pocas de las manifestaciones en que se plasma la libertad (artículo 17), por su- 
puesto, las manifestaciones y reuniones en lugares de tránsito público (artículo 21), o el derecho a la libre circulación (artículo 19).

7. Por último, una partida destacada en la que la frecuencia del ámbito privado se conjuga con destacadas opciones que reclaman la presencia en la calle.

- La libertad de expresión (artículo 20) de que disfruta quien está escribiendo una novela o redactando un comentario de jurisprudencia en su casa, se entremezcla con espacios para la oratoria en las plazas, anunciadores y distribuidores de propaganda, mítines al abierto, etc.

- La creación artística (artículo 20) nos evidencia la frecuencia en la calle de las obras o actuaciones de escultores - ese tesoro de la estatuaria pública de tantas de nuestras ciudades-, pero también de pintores o de músicos.

- La libertad religiosa (artículo 16) cuenta también de manera señalada, junto al culto que se celebra en los templos, o la enseñanza, por ejemplo del catecismo en las parroquias, o del Corán en las madrazas, con los actos de testimonio en las calles, como todas las variedades de procesiones y actos similares, actividades de proselitismo, llevanza de símbolos, o de vestimentas, etc.

- El deporte y la educación fisica (artículo 43.3), junto a todo tipo de sedes estables, como piscinas, estadios, polideportivos, etc., ofrece también otras variantes, así, junto al pavor que nos causa el asesino de la bicicleta, que aparece impensadamente y de sopetón en los lugares que uno considera reservados a los peatones, el gusto de ver a quienes van corriendo por la calle, o el recuerdo de cuando de niños podíamos jugar con la pelota en la plaza delante de casa, o el grato espectáculo de cuando pasa por la calle principal la masa de quienes corren la maratón, cualquier otra carrera, o la serpiente de la vuelta ciclista. Sin dejar de contar esos espacios urbanos que cada grupo o club utiliza para la celebración de los triunfos de su equipo.

8. El dato real es que la calle va a resultar lugar propicio y necesario para el ejercicio de muy cualificados derechos fundamentales o de algunas de sus manifestaciones. De ahí su señalada importancia al respecto, lo que nos lleva a plantear algunos interrogantes decisivos. Porque podría actuarse con fluidez y sin enfrentamientos, pero la experiencia enseña que, sin duda, la calle es un bien escaso, en el que puede haber con frecuencia aspiraciones contradictorias, roces, tensiones, incluso enfrentamientos y conflictos, que exigen por fuerza reglas y control y vigilancia. De ahí interrogantes como éstos: ¿Cómo se gestiona y administra la calle? Incluso, la clásica y reiterada pregunta, ¿de quién es la calle? O, ¿habrá que establecer criterios para usarla?

Es así como las reglas y criterios de Derecho constitucional, al diseñar cada uno de los derechos y libertades, van a necesitar el auxilio de las reglas y criterios del De- 
recho administrativo, del Derecho civil incluso. Lo que nos lleva a recordar el lúcido planteamiento de Ernst Forsthoff y otros autores alemanes, de que el Derecho constitucional necesitará de las fórmulas y criterios del Derecho administrativo para hacerse efectivo. Se cuenta, en efecto, con una ordenación jurídica de los espacios públicos, que será decisiva e, incluso, necesaria, para el efectivo y correcto uso de los mismos: es así como se facilitará la virtualidad de los derechos fundamentales a la par que se tratan de evitar o resolver las tensiones que puedan producirse. De ahí la utilidad de parar mientes en unos cuantos preceptos decisivos de nuestro sistema jurídico.

\section{LA CALLE Y SU REGULACIÓN JURÍDICA}

9. El sistema jurídico dedica especial atención a las vías públicas. Ante todo, como punto de partida de los planteamientos tradicionales, el artículo 344 del Código Civil ofrece un claro y expresivo planteamiento: "Son bienes de uso público, en las provincias y los pueblos, los caminos provinciales y los vecinales, las plazas, calles, fuentes y aguas públicas, los paseos y las obras públicas de servicio general costeadas por los mismos pueblos o provincias", debiendo destacarse la significativa referencia al "uso público". Similar resulta el artículo 339, referido ahora al Estado: "Son bienes de dominio público, $1^{\circ}$. Los destinados al uso público, como los caminos (...), puertos y puentes construidos por el Estado (...)".

Por su parte, resultan de especial interés las fórmulas que ofrece el sistema de Derecho administrativo, con su atención a los bienes públicos, con significativas referencias así en la legislación local. Por tomar un ejemplo bien gráfico, el Texto Refundido de las Disposiciones en Materia de Régimen Local, R.D. Legislativo 781/1986, puntualiza en su artículo $74.1^{2}$, que "Son bienes de uso público local los caminos y carreteras, plazas, calles, paseos, parques, aguas, fuentes, canales, puentes y demás obras de aprovechamiento o utilización generales cuya conservación y policía -recalcaré lo de policía- sean de competencia de la entidad local". Siempre el peso de la referencia al "uso público".

Se ha producido una destacada inflexión conceptual: según la tradicional fórmula del Código Civil, la referencia al uso público se consideraba inspirada en el criterio de Proudhon de que lo que primaba era garantizar el uso público, sin darle importancia al aspecto de la titularidad. En cambio, a la vista de la más reciente legislación local, la doctrina mayoritaria -sin que falten otras interpretaciones-, se inclina

${ }^{2}$ Literalmente reproducido en el artículo 3 del Reglamento de Bienes de las Entidades Locales, R.D. 1372/1986, de 13 de junio. 
a poner el acento en la consideración de dichos bienes como de propiedad del ente local $^{3}$. En cuanto la sociedad se hizo más compleja, la concepción proudhoniana resultaba débil a la hora de la protección de dichos bienes, y exigía algo más, inimaginable, de acuerdo con las concepciones de la época, que los bienes referidos pudieran tener acceso al Registro de la Propiedad. De ahí el acierto de utilizar en apoyo el concepto de propiedad. Pero ni que decir tiene que esta fórmula de la propiedad no tiene ninguna connotación nacionalizadora o socializante, es, sobre todo, una técnica jurídica adecuada de distribución, especialmente válida para impedir apropiaciones impertinentes y tratar de asegurar el uso más adecuado.

En este sentido, resultan de gran utilidad las precisiones contenidas en el citado Reglamento de Bienes de las Entidades Locales, bien conocidas, sin duda, pero que conviene recordar ahora, dado que ofrecen interesantes concreciones funcionales. Se considerará, así, uso común, según el artículo 75.1, el correspondiente por igual a todos los ciudadanos indistintamente, de modo que el uso de unos no impida el de los demás interesados. Dando un paso más, dentro de él, en concreto, "El uso común general de los bienes de dominio público - artículo 76- se ejercerá libremente con arreglo a la naturaleza de los mismos, a los actos de afectación y apertura al uso público y a las leyes, reglamentos y demás disposiciones generales". Sobre este precepto he de volver enseguida. Pero antes, he de referirme a otro concepto que completa el panorama, cual es el de uso privativo, en principio contrapuesto al anterior, de forma que será "uso privativo, el constituido por la ocupación de una porción de dominio público, de modo que limite o excluya la utilización por los demás interesados" (artículo 75.2). Con la característica de que el uso privativo, como principio, estará sujeto a concesión administrativa (artículo 78.1.a). Entre medio, queda el supuesto de uso común especial, caracterizado con el canon de intensidad, y que se sujeta a licencia (artículos 75.1.b y 77.1). De gran utilidad, también, desde una perspectiva más amplia, las previsiones que ofrece el artículo 6 de la Ley del Patrimonio de las Administraciones Públicas, la 33/2003, de 5 de noviembre, que, bajo el rótulo "Principios relativos a los

\footnotetext{
${ }^{3}$ Sobre dicha polémica y sus orígenes, véase Germán FERNÁNDEZ FARRERES, Sistema de Derecho Administrativo II, $2^{\text {a }}$ ed., Civitas, 2014, 272 ss., donde se destaca el papel pionero que desempeñó M. Hauriou en la consideración del dominio público como una propiedad. Un planteamiento novedoso y brillante en dicha polémica, apartándose del concepto de propiedad, en Luciano PAREJO ALFONSO, Dominio público: un ensayo de reconstrucción de su teoría general, en "Revista de Administración Pública”, 100-102 (1083), 2379 ss. Véase también, Julio GONZÁLEZ GARCÍA, La titularidad de los bienes del dominio público, Ed. Marcial Pons, Madrid, 1998. Sobre la decidida postura del Tribunal Constitucional sosteniendo el concepto de propiedad, véase Eloy COLOM PIAZUELO, La configuración jurídica del dominio público en la jurisprudencia constitucional: el dominio público como una propiedad pública fuera del comercio destinada a fines públicos, en "Administración y Justicia. Liber Amicorum Tomás-Ramón Fernández", volumen I, Civitas, 2012, 103 ss. Resaltando como "los bienes de dominio público se configuran como una propiedad pública", págs.. 107 ss.
} 
bienes y derechos de dominio público", contiene, entre otras, las siguientes previsiones: "La gestión y administración de los bienes y derechos demaniales por las Administraciones Públicas se ajustarán a los siguientes principios: (...) c) Aplicación efectiva al uso general o al servicio público, sin más excepciones que las derivadas de razones de interés público debidamente justificadas. / d) Dedicación preferente al uso común frente a su uso privativo. / e) Ejercicio diligente de las prerrogativas que la presente Ley u otras especiales otorguen a las Administraciones Públicas, garantizando su conservación e integridad". Recalcaré que junto al énfasis que se pone en el uso común ${ }^{4}$, se insiste especialmente para que las Administraciones supervisen y controlen estos bienes.

10. A modo de recapitulación, cabe destacar unas cuantas conclusiones de lo que acaba de indicarse.

- Hay que tomar nota de la insistencia en el uso público de los citados bienes demaniales.

- Con todo, resulta claro que el municipio figura como propietario de la calle, en el sentido amplio de vías públicas, que incluye toda clase de calles -independientemente de cómo se denominen-, plazas, parques y jardines, etc.

- Como propietario, el municipio ostenta todos los poderes y cargas inherentes a dicha condición: administrar, cuidar, tutelar y vigilar, defender, así como responder de los posibles daños.

- He de poner énfasis en la referencia a la policía, contenida en el artículo 74.1 del Texto Refundido, recalcando además el contenido del artículo 76 del Reglamento de Bienes, que al contemplar el uso común general insiste en que la utilización de los bienes habrá de hacerse de acuerdo con la naturaleza y afectación de los mismos, así como respetando las leyes, reglamentos y demás disposiciones.

- La llamada a las leyes invita a recordar que las leyes que regulan cada uno de los derechos fundamentales pueden incluir exigencias obligatorias no sólo para los ciudadanos sino de manera especial para el propio ayuntamien-

4 También en las leyes sectoriales se encuentran referencias a la importancia del uso común. Ejemplo bien indicativo me parece el caso de la Ley de Costas, la 22/1988, de 28 de julio, que en su título III, sobre "Utilización", contiene en el artículo 31.1 la siguiente exigencia: "La utilización del dominio público marítimo terrestre y, en todo caso, del mar y su ribera será libre, pública y gratuita para los usos comunes y acordes con la naturaleza de aquel, tales como pasear, estar, bañarse, navegar, embarcar y desembarcar, varar, pescar, coger plantas y mariscos y otros actos semejantes que no requieran obras e instalaciones de ningún tipo, y que se realicen de acuerdo con las leyes y reglamentos o normas aprobadas conforme a esta ley". 
to. Luego se tratará de la Ley de Reuniones, pero cabe recordar también lo que dispone la Ley Electoral, la de Libertad Religiosa, la de Seguridad Ciudadana, etc.

- Lo que lleva a considerar que sobre esos espacios de propiedad municipal podrán ejercerse también las potestades que contemplan dichas leyes y, señaladamente, además de la derivada del poder de policía municipal, revestirá especial significado en ocasiones la atinente al poder de policía de los cuerpos de seguridad, ya sean estatales o, en su caso, autonómicos ${ }^{5}$.

11. La remisión que el artículo 76 del Reglamento de Bienes hace a las leyes, reglamentos y disposiciones generales, da oportunidad para referirse de manera especial a las ordenanzas municipales, que van a desarrollar un papel muy destacado en este campo. Se trata de un instrumento muy vivo en la práctica municipal, con enorme incidencia en la vida cotidiana, decisivo también para marcar exigencias en relación con el ejercicio de los derechos fundamentales. Con carácter general, las ordenanzas municipales marcan exigencias, acotan espacios, prohíben usos y dirigen en gran medida la vida de la ciudad o pueblo. Me remitiré así, por el rico contenido sobre los

${ }^{5}$ Recuérdese que la Ley Reguladora de las Bases de Régimen Local, la 7/1985 de 2 de abril, artículo 25.2, muy modificado por la Ley de Racionalización y Sostenimiento de la Administración Local, la 27/2013, de 27 de diciembre, otorga competencia al municipio "en los términos de la legislación del Estado y de las Comunidades autónomas", entre otras materias, en policía local, protección civil (f), infraestructura viaria y otros equipamientos de su titularidad (d), tráfico, estacionamiento de vehículos y movilidad (g), protección de la salubridad pública (j), o evaluación e información de situaciones de necesidad social y la atención inmediata a personas en situación o riesgo de exclusión social (e). Véase sobre la problemática que plantea la nueva regulación, Julia ORTEGA BERNARDO, Derechos fundamentales y ordenanzas locales, Marcial Pons, Madrid, 2014, 338 ss. Por su parte, y por citar ahora un solo ejemplo, recuérdese que la Ley de Protección de la Seguridad Ciudadana, la Orgánica 1/1992, de 21 de febrero, a punto de modificarse significativamente, una vez que el apartado primero de su artículo dos enumera cuáles serán las autoridades del Estado competentes en principio en materia de seguridad, el apartado dos de dicho artículo precisa: "Sin perjuicio de lo dispuesto en el apartado anterior, las autoridades locales seguirán ejerciendo las facultades que les corresponden de acuerdo con la Ley Orgánica de Fuerzas y Cuerpos de seguridad y la legislación de Régimen Local, Espectáculos Públicos y Actividades Recreativas, así como de Actividades Molestas, Insalubres, Nocivas y Peligrosas.

Y es que conviene tener en cuenta, como recalca FERNÁNDEZ FARRERES, que de acuerdo con el actual sistema constitucional español no siempre coincide propiedad con titularidad de competencias. Dice así el profesor de la Complutense, "Las Administraciones titulares de bienes de dominio público no pueden por razón de esa titularidad disponer de competencias que, incidiendo en los mismos, constitucionalmente no les hayan sido atribuidas. Ello quiere decir, desde la perspectiva opuesta, tal como ha destacado reiteradamente la jurisprudencia constitucional (...), que, al no ser el dominio público, ni la propiedad de cualesquiera otros bienes inmuebles, título competencial, sobre los mismos se pueden proyectar competencias de otros entes distintos" (Sistema de Derecho Administrativo, II, cit., 290-291). 
efectos de la figura, a los interesantes trabajos de Juan Pemán Gavín ${ }^{6}$ y de Juan Manuel Trayter ${ }^{7}$, elaborados a propósito de la tan destacada Ordenanza de Civismo de la ciudad de Barcelona, tan innovadora y con tan sugerentes propuestas. Yo mismo abordé el tema de alguna manera al reflexionar en 2010 sobre los ayuntamientos y el régimen jurídico de atuendos y vestimentas ${ }^{8}$. Y últimamente acaba de aparecer, desde una perspectiva global, el libro de Julia Ortega Bernardo ${ }^{9}$ sobre "Derechos fundamentales y ordenanzas locales", que se citó.

Hecha esta referencia, no es éste el momento para insistir sobre las ordenanzas municipales. Aunque no debo pasar por alto una significativa observación sobre la que había insistido Juan Pemán ${ }^{10}$ : el peligro de que la ordenanza, tan incisiva a veces, carezca del imprescindible soporte legal a la hora de ordenar determinadas conductas. Alguna referencia al tema se hará más adelante.

\section{LÍMITES DE LOS DERECHOS FUNDAMENTALES, EN ES- PEGIAL, EL RESPETO A LOS DEREGHOS DE LOS DEMÁS}

12. La rica vida de los derechos y la constante manifestación de alguno de ellos en la calle exige, como contrapeso, que se pare mientes en el aludido aspecto de los límites. No es cuestión baladí, al contrario, de la más viva actualidad, suscitando problemas de continuo en la vida cotidiana. A veces no estará claro hasta donde alcanzan los derechos, si bien no es infrecuente que quienes ejerciten un derecho se con-

${ }^{6}$ Juan PEMÁN GAVÍN, Ordenanzas municipales y convivencia ciudadana. Reflexiones a propósito de la Ordenanza de civismo de Barcelona, en el volumen colectivo "Derechos fundamentales y otros estudios sobre derechos humanos en homenaje al Prof. Dr. Lorenzo Martín-Retortillo", I, El Justicia de Aragón, Zaragoza, 2009, 497 ss. Del mismo Juan PEMÁN, La política de civismo de los ayuntamientos españoles. Entre policía, acción social y educación cívica, ponencia expuesta en el Seminario "30 años de ayuntamientos democráticos, con especial referencias a los derechos de los ciudadanos", celebrado en el Departamento de Derecho Administrativo de la Facultad de Derecho de la Universidad Complutense, en 2010, por cuya versión se cita, aparecida luego en la "Revista Aragonesa de Administración Pública".

${ }^{7}$ Joan Manuel TRAYTER JIMÉNEZ, Las ordenanzas cívicas: especial referencia a la Ordenanza de convivencia ciudadana de Barcelona, en el volumen colectivo "Derechos fundamentales y otros estudios", citado en la nota anterior, I, 537 ss.

${ }^{8}$ Lorenzo MARTÍN-RETORTILLO, Los ayuntamientos y el régimen jurídico de atuendos y vestimentas, "Anuario del Gobierno Local”, 2010, páginas 341 ss.

${ }^{9}$ Julia ORTEGA BERNARDO, Derechos fundamentales y ordenanzas locales, Marcial Pons, Madrid, 2014.

${ }^{10}$ Juan PEMÁN GAVÍN, La politica de civismo, cit., página 28. 
sideren habilitados para campar a sus anchas, sin importarles que sus actuaciones desborden lo correcto y lo permitido. Por lo que aparece también el interés por ver en qué medida reacciona la autoridad administrativa, que es tanto como decir, de qué manera se protegen los derechos de los terceros. Del rico catálogo de posibles muestras, he seleccionado tres ejemplos, que me parecen de sobras expresivos. Aludiré ante todo al derecho de manifestación, después a algunas variantes de ocupación irregular de la calle y, en tercer lugar, a la política de prohibición de algunas vestimentas. Aspectos bien variados que darán pie a sugestivas reflexiones.

\section{A. Doble faz del derecho de manifestación}

La experiencia cotidiana de las manifestaciones ofrece inmejorable testimonio para valorar el canon de respeto a los terceros, que se proyecta además en una doble dirección. La Ley sobre el Derecho de Reunión, la Orgánica 9/1983, de 15 de julio, que ha suscitado muy rica bibliografía a la que me remito ${ }^{11}$, contiene una acertada fórmula, que parece satisfactoria, y sobre todo funcional. Otra cosa es que no se respete, como sucede en ocasiones. Los artículos 8 y 9 , referidos a las reuniones en los lugares de tránsito público y manifestaciones, contemplan el requisito de un preaviso "a la autoridad gubernativa", con una antelación en principio de diez días, en el que, aparte del lugar, fecha, itinerario, hora y duración prevista, deben hacerse constar "las medidas de seguridad previstas por los organizadores o que se soliciten de la autoridad gubernativa". Asoma, en efecto, el tema de la protección de los manifestantes, tan importante a la vista de la experiencia, pues a veces asoman temas o situaciones, especialmente calientes, aparte de que nunca llueve a gusto de todos, y hay cuestiones que si vitales para algunos pueden suscitar rechazo en otros, y iquién sabe lo que podría suceder!

Se hablaba de la "autoridad gubernativa", y el ayuntamiento, el dueño de la calle, ¿tendrá algo que decir? En 1999 se modificó la regulación para dar voz al ayuntamiento, responsable entre otras cosas, no se olvide, del tráfico local ${ }^{12}$. Ahora, al re-

11 Con tantas aportaciones interesantes, desde el temprano comentario a la Ley de Piedad GARCÍA ESCUDERO y Benigno PENDÁS, los trabajos de Manuel PULIDO QUECEDO, Juan SANTAMARÍA PASTOR, Antonio EMBID IRUJO, Pedro Luis SERRERA CONTRERAS, o los libros de Ignacio TORRES MURO, y José Luis LÓPEZ GONZÁLEZ, entre otros.

12 Recuérdese, aparte de lo señalado en la nota 5, que el Real Decreto Legislativo 339/1990, de 4 de marzo, aprobando el Texto Articulado de la Ley de Seguridad Vial, atribuye competencia a los Municipios, entre otras, en la siguiente materia: "La regulación mediante Ordenanza Municipal de Circulación, de los usos de las vías urbanas, haciendo compatible la equitativa distribución de los aparcamientos entre todos los usuarios con la necesaria fluidez del tráfico rodado y con el uso peatonal de las calles (...)". 
cibir el preaviso la autoridad gubernativa, se dirige al ayuntamiento para que informe sobre las circunstancias del recorrido propuesto, refiriéndose a causas objetivas como el estado de los lugares, la concurrencia con otros actos, las condiciones de seguridad y otras análogas. La autoridad gubernativa, en atención a razones de orden público o de peligro para personas o bienes puede introducir modificaciones en las previsiones, como alterar el itinerario, la duración o la fecha o, incluso prohibirla. Se trata de opciones lógicas, que tienen que tener un fundamento objetivo, y cuya discusión, como es bien sabido ha dado abundante trabajo a nuestros Tribunales.

Sin duda, el conocimiento previo resulta elemental para adoptar las medidas necesarias en la complicada vida de nuestros días, medidas entre las que hay que contar con la organización de los medios para defender a los manifestantes de posibles agresiones. El Tribunal Constitucional en su sentencia 59/1990, de 29 de marzo, ha puntualizado que no se trata de una autorización "sino tan sólo de efectuar una declaración de ciencia o de conocimiento a fin de que la autoridad administrativa pueda adoptar la medidas pertinentes para posibilitar tanto el ejercicio en libertad del derecho de los manifestantes como la protección de los derechos y bienes de la titularidad de terceros". Y es que, en efecto, va a aparecer un doble frente que hay que considerar sin falta.

13. De una parte, los manifestantes deben respetar los bienes y derechos de los demás. Se trata de una afirmación de enorme contenido, que se desdobla a su vez en una serie de exigencias. Hay que decir que la inmensa mayoría de las manifestaciones funcionarán con normalidad y civismo Hablamos en principio de las manifestaciones lícitas, en las que se han cumplido los requisitos que marca la ley. Pero hay que tenerlo todo previsto. La experiencia enseña que de vez en cuando aparecen manifestaciones que no respetan las reglas, habiendo en algunas ocasiones supuestos extremos, con brotes de violencia, incluso, que pueden demandar la aplicación de la Ley de Seguridad Ciudadana ${ }^{13}$ o, incluso, del Código Penal, artículos 513 y 514.

${ }^{13}$ Recuérdese que entre los objetivos de la Ley de Protección de la Seguridad Ciudadana, la Orgánica 1/1992 de 21 de febrero, figura, como se afirma en el artículo 1.1, el "proteger el libre ejercicio de los derechos y libertades y garantizar la seguridad ciudadana, crear y mantener las condiciones adecuadas a tal efecto, y remover los obstáculos que lo impidan". Por su parte, el artículo 16.1 de la misma Ley, dispone que "Las autoridades a las que se refiere la presente Ley adoptarán las medidas necesarias para proteger la celebración de reuniones o manifestaciones o de espectáculos públicos, procurando que no se perturbe la seguridad ciudadana (...)". Y en el apartado 2 de dicho precepto, se indica: "Dichas autoridades, por medio de la Fuerzas y Cuerpos de Seguridad, podrán disolver, en la forma que menos perjudique, las reuniones en los lugares de tránsito público, y las manifestaciones, en los supuestos prevenidos en el artículo 5 de la Ley Orgánica 9/1983, de 15 de julio, Reguladora del Derecho de Reunión (...)”. 
Por cierto que, en otra dirección, no dejaré de señalar un curioso contraste. En muchos países, sobre todo en las manifestaciones de escasa concurrencia, advertimos que los manifestantes marchan por las aceras, dejando libre la calzada, para no perturbar la circulación y paralizar lo menos posible la vida de la ciudad. Ese canon de respeto cívico no impide que los manifestantes puedan lograr sus objetivos y hacer ostensibles sus reivindicaciones o propuestas, o su simple presencia, causando las menores molestias posibles a los demás. Fórmula que obviamente no encaja para las supernumerosas, pero que yo estimo válida y correcta para la mayor parte de manifestaciones, con un número contenido de personas. Pero aquí parece que se ha apostado por la fórmula del todo o nada, desde la idea de que hay que alterar el régimen de la ciudad y causar perjuicios y molestar a los demás para que a uno le hagan caso. Cuando está claro que se puede ejercitar un derecho y desarrollar todas sus virtualidades desde una postura de respeto a los demás. ¡Cuesta mucho aprender los cánones del civismo! ${ }^{14}$

${ }^{14}$ El Tribunal Constitucional ha sido enormemente tolerante en este punto concreto, como testimonio de esa característica tan española de los últimos años, de que, tras el anterior periodo de privación de libertades, se asume casi la idea de que todo deberá estar permitido ahora. Por ejemplo, en la sentencia, de amparo, 66/1995, de 8 de mayo, afirmaba: "Aplicando estas premisas al caso de las concentraciones que afectan a la circulación de vehículos por las vías de tránsito público lo primero que cabe afirmar es que sólo en supuestos muy concretos podrá concluirse que la afectación del tráfico conlleva una alteración del orden público con peligro para personas o bienes. Es cierto que la paralización del tráfico con la finalidad primordial de alterar la paz pública no constituye un objeto integrable en el derecho de reunión en lugares de tránsito público, cuyo objeto, como hemos expuesto anteriormente, es el intercambio y la comunicación pública de ideas y reivindicaciones. Sin embargo, no es menos cierto que por su propia naturaleza el ejercicio de ese derecho requiere la utilización de los lugares de tránsito público y, dadas determinadas circunstancias, permite la ocupación, por así decir, instrumental de las calzadas. En suma, la celebración de este tipo de reuniones puede producir trastornos y restricciones en la circulación de personas y, por lo que aquí interesa, de vehículos que se ven impedidos de circular libremente por el lugar en que se celebra la reunión (STC 59/1990). En una sociedad democrática, el espacio urbano no es sólo un ámbito de circulación, sino también un espacio de participación". Uno podría pensar que hay espacio para todos, pero que son convenientes los repartos funcionales, salvo supuestos muy excepcionales. En la misma sentencia se insiste en la idea, en estos términos: "no cualquier corte de tráfico o invasión de calzadas producido en el curso de una manifestación o de una concentración puede incluirse en los límites del artículo 21.2 CE. Para poder restringir el ejercicio del derecho de reunión deberán ponderarse caso a caso, todas las circunstancias específicas concurrentes en cada una de las reuniones que pretendan llevarse a cabo al objeto de determinar si efectivamente existen razones fundadas para creer que el colapso circulatorio tendrá las características y los efectos antes descritos. Por ello no puede admitirse, como bien advierte la recurrente, la afirmación genérica de que determinadas calles o zonas de una ciudad no son idóneas para el ejercicio del derecho de manifestación o de reunión debido a la densidad de tráfico que circula por ellas por término medio. Para prohibir las reuniones no puede invocarse una 
Siguiendo con la referencia al respeto de los bienes y derechos de los demás, la Ley aborda la cuestión de manera directa, con una doble referencia complementaria. De una parte, el artículo 4.2 dispone, ante todo, que del buen orden de la manifestación "serán responsables sus organizadores quienes deberán adoptar las medidas para el adecuado desarrollo de las mismas". En 1997 se modificó el apartado 3 de dicho artículo 4, de forma que ahora contiene destacadas previsiones: "Los participantes en reuniones o manifestaciones, que causen un daño a terceros, responderán directamente de él". Pero hay un segundo escalón, pues como se dice a continuación, "Subsidiariamente, las personas naturales o jurídicas organizadoras o promotoras (...), responderán de los daños que los participantes causen a terceros ${ }^{15}$, sin perjuicio de que puedan repetir contra ellos, a menos que hayan puesto todos los medios razonables a su alcance para evitarlos"16.

En conclusión, el régimen jurídico del derecho de manifestación implica que los organizadores asumen compromisos y responsabilidades, y deben estar dispuestos a ejercer su autoridad para asegurar el correcto funcionamiento de la marcha.

14. Pero junto a esa línea que reclama respeto a los manifestantes, hay también exigencias en sentido contrario. No en balde, la manifestación es un derecho que, mientras se ejercite en el terreno de lo lícito, debe ser por eso protegido y garantizado. De ahí la obligación de las autoridades de protegerlo. Y aquí pasa un poco lo que antes decía: la mayoría de manifestaciones, no van a plantear problema alguno. Pero hay temas polémicos, que pueden enfrentar a la población, y también la experiencia enseña la existencia de "reventadores", contramanifestantes, o quienes están dispuestos a oponerse o a perturbar el derecho de manifestación de algunos. De ahí nuevamente la importancia del preaviso: permite adoptar previsiones para los supuestos que puedan resultar polémicos o incompatibles. Hace algunos años insistía en esta necesaria protección y en la consecuencia obvia de adoptar medidas, en aque-

genérica conflictividad circulatoria..." Pienso, en cambio, que sería muy legítimo que los Ayuntamientos, procediendo con prudencia y moderación, pudieran señalar determinados espacios como específicamente destinados a fines concretos, y excluidos por tanto del ámbito de las manifestaciones. He tomado el texto de la sentencia citada de Manuel PULIDO QUECEDO, Constitución Española, $4^{a}$ ed., Aranzadi, 2005, 512 ss.

${ }^{15}$ Véase José Luis LÓPEZ GONZÁLEZ, El derecho de reunión y manifestación en el ordenamiento constitucional español, Ministerio de Justicia, Madrid, 1995, 245 ss., donde se hace una revisión de la jurisprudencia que, por cierto, resulta mayoritariamente opuesta a las pretensiones de la Administración de que los organizadores satisfagan los daños causados.

${ }^{16} \mathrm{~J}$. L. LÓPEZ GONZÁLEZ, op. cit., 244, toma partido con fuerza, y creo que acertadamente, frente a la tesis de Antonio EMBID IRUJO de que sería conveniente "socializar" los posibles daños causados por los manifestantes, y cargárselos a la Administración. 
llos casos patéticos cuando en el País Vasco se manifestaban silenciosamente quienes querían lamentarse de un reciente asesinato, ${ }^{17}$ y se encontraban al lado mismo con una barrera que les acogotaba y perturbaba ${ }^{18}$. Hay una temprana sentencia del Tribunal Europeo de Derechos Humanos, bien interesante, en la que éste dejó sentado que el Estado, ante las manifestaciones, debía no sólo permitirlas, sino adoptar medidas positivas para proteger a los manifestantes. Se trataba, en efecto, de una cuestión que todavía acredita la viva tensión entre partidarios y detractores: la sentencia "Plattform Ärzte für das Leben c. Austria", 14.V.1989, se refería, en efecto, a manifestantes contrarios al aborto, cuya carrera había sido interferida por los abortistas. El Tribunal Europeo deja sentado con claridad este principio de la obligación positiva del Estado de defender a los manifestantes, si bien no se termina condenando a Austria, dado que había adoptado medidas, que luego resultaron insuficientes, siendo desbordados por los abortistas. Similar línea ha sido asumida en España con normalidad. Javier Barcelona comentó la sentencia del Tribunal Supremo de 28 de octubre de 1986, referente a una manifestación de antiabortistas en Pamplona: se produce agresión de los contramanifestantes, que llegaron incluso a romper la instalación de megafonía, y el Supremo condenó al Estado a indemnizar.

En suma, deber de respeto por parte de los manifestantes en relación con los bienes de los demás, pero, a la par, necesidad de proteger y garantizar el derecho de manifestación.

${ }^{17}$ En un trabajo de recapitulación para celebrar los 25 años de la Constitución (Los derechos fundamentales y la Constitución a los 25 años, recogido ahora como capítulo 13, de mi volumen recopilatorio "Los derechos fundamentales y la Constitución", editado por El Justicia de Aragón, Zaragoza, 2009, páginas 306-307), tenía ocasión de indicar: "No es correcto impedir, <chafar > o < reventar>, el mitin, la manifestación o el acto de culto de los demás. Con frecuencia, los periodistas jalean a los $<$ reventadores> y celebran y sonríen < sus gracias>, sobre todo si afectan a conocidos líderes, pero cualquiera sabe que según los cánones democráticos, son actuaciones que no tienen legitimación alguna. Diría más aún. Forma parte del derecho de reunión, o del de manifestación, el ser respetado, incluso, el ser dejado solo. Nada impide que, dentro de la ley, uno manifieste las ideas que quiera, pero es necesario que se produzca un reparto de los espacios y de los tiempos. No caben interferencias. No es legítimo, en absoluto, por tanto, que se sitúen inmediatamente al lado de quienes hacen público un sentimiento, los que, defendiendo lo contrario, están, de hecho, por activa o por pasiva, coartando o increpando a los contrarios. En democracia, el derecho de manifestación no tiene por qué ser un acto de heroísmo. Alguien tiene que amparar y tutelar la normalidad. Insisto en que es decisivo un reparto del tiempo y, en su caso, del espacio. No habrá que prohibir la <contramanifestación>, pero sí situarla en otro lugar o a otra hora"

${ }^{18}$ Muy interesantes también las reflexiones que sobre las manifestaciones junto al parlamento formulaba Fernando SAINZ MORENO, Reuniones y manifestaciones ante la sede de los parlamentos, "Cuadernos de Derecho Público", núm. 15 (2002). 


\section{B. Algunas peculiares ocupaciones irregulares de las vías públicas}

15. La segunda variante que quiero reseñar, si bien sucintamente, aunque no es un problema trivial, me lleva a la práctica, relativamente frecuente en tantas ciudades españolas, de quienes ilegalmente ocupan calles o plazas impidiendo el normal disfrute de los demás. Se recordó la vocación de uso común general que caracteriza a las vías públicas, así como que determinados usos de especial intensidad requerían alguna modalidad permisiva por parte del ayuntamiento. Y eso es lo que sucede con carácter general, en la que tantos usos tradicionales cuentan con la requerida concesión, autorización o previsión expresa en las ordenanzas municipales, desde puestos prolongación del mercado a mercadillos periódicos, o las ferias para las fiestas, los que se ganan la vida haciendo de estatua en las esquinas del centro en un incesante ¡más difícil todavía!, los predicadores o mitineros callejeros, los actores o bailaores improvisados, los cantores y músicos, ya sea tocando el arpa, el saxofón, el acordeón o el violín, ya en grupo, estilo mariachi, o con flautas andinas o acaso instrumentos de cuerda con repertorio clásico, etc., etc.: una variada gama de usos, insisto, tan vinculados a la vida de la ciudad, que, en general, ni molestan ni perturban. Pero hay otros usos auténticamente anómalos, que sin duda perturban y molestan, tan presentes en no pocas ciudades, que se adueñan intensamente de la calle, ya sea por razones políticas o por otras circunstancias sociales más complejas. Frente a los que, con frecuencia, quienes tendrían que reaccionar no reaccionan, ya sea por no poder abordar a fondo el problema, por no complicarse la vida o, incluso, por el complejo de que ejercer la legítima autoridad pudiera ser considerado autoritario. Cualquiera conocerá abundantes supuestos. Pondré tres ejemplos, variantes bien cercanas, que cualquiera podrá - o habrá podido- observar en la ciudad en que vivo, Madrid.

En una de las plazas más hermosas de la ciudad -la de La Provincia-, sede tradicional del Ministerio de Asuntos Exteriores, en cuyo centro hay un pequeño y bien interesante monumento, por su formato y por el acontecimiento que recuerda - el ingreso de España en lo que hoy es la Unión Europea-, han acampado durante muchos meses, de día y de noche, utilizando el monumento para apoyar su habitáculo - que perdió así cualquier sentido monumental-, un grupo de personas provenientes de una isla del Caribe, haciendo alarde de no sé qué reivindicaciones. Nadie debió recordarles que eso no se podía hacer, que nadie puede ocupar indebidamente los espacios públicos, que el sistema democrático ofrece sobrados medios para plantear las reivindicaciones políticas, nadie les debió exigir autorización ni concesión alguna, ni menos cobrar la tasa que pagan puntualmente los usuarios habituales del dominio público, y allí estuvieron meses y meses, hasta que un buen día por las buenas desaparecieron.

Hay situaciones más complejas, que en otros sitios se abordan y que, aunque sea un problema delicado, parece que de alguna manera habría que abordar. Es el caso de quienes instalan sus cartones o sus sacos, y pernoctan, no bajo los puentes, como 
en las antiguas crónicas, sino donde se les ocurre, aunque sea en la plaza más importante y más céntrica. Otro ejemplo parecido: justo donde terminan los jardines del Palacio Real, en la rampa de la misma puerta de entrada, a eso del atardecer, cuando todavía se circula por ahí entrando y saliendo, instalan su campamento -bultos, cartones, colchonetas, transistores, etc.-, un crecido número de personas provenientes de un país del Este, que aun con los rigores del invierno pernoctarán bajo las estrellas. Al margen de otras consideraciones, importan muy mucho las condiciones sanitarias del entorno: no hay que decir los olores que la concentración emana y la peste que tienen que aguantar quienes por allí han de pasar, en un lugar en que se circula con normalidad, impresionados los niños de ver tan lamentables situaciones.

El primer ejemplo, no tiene justificación alguna en mi opinión: alguien tendría que haber recordado que en un país democrático como España hay muchas maneras de sostener las reivindicaciones políticas, sin tener que hacer un uso abusivo de los bienes públicos a todos destinados. Y aparte de otras razones que acaso pesen más, no se pueden olvidar los motivos estéticos: es legítimo que los ciudadanos aspiren a tener una ciudad grata y placentera -la tradicional referencia al "ornato" de nuestros textos legales-, sin que sea justificable el caprichoso deterioro de lugar especialmente cualificado porque haya unos señores que aterricen porque sí. Los dos últimos ejemplos son, en cambio, mucho más complejos. Ante todo, aparecen los sentimientos de piedad y conmiseración, a la vista de las duras circunstancias que tienen que soportar. En frío, es una situación verdaderamente terrible, que impresiona. Viene en mientes enseguida el pensamiento en los servicios sociales, que deberían llegar a cubrir esas necesidades, intentando abordarlas desde las más variadas opciones y necesidades, con el ofrecimiento dialogado de alternativas incluso. ¿Es que no funcionan? ¿Es que no alcanzan cubrir tales necesidades? Habría que insistir con fuerza en esta línea. También podría suceder que hubiera un rechazo expreso por parte de los afectados, que por lo que sea se nieguen a aceptar las condiciones de los servicios sociales. Pero, en tal caso, y una vez agotado el intento de encontrar fórmulas satisfactorias en la medida en que lo permita la organización de los servicios, no se justifica en absoluto la tolerancia y permisividad. Las razones sanitarias son decisivas, decía. Pero tampoco se justifica ese desorden que afecta a espacios que son de todos y para todos. Bien sabemos que la vida y la ciudad, son complejas y que hay de todo. Recordemos el diálogo de Crispín con Leandro al inicio de "Los intereses creados" de Jacinto Benavente: "Dos ciudades hay (...) Digo dos ciudades como en toda ciudad del mundo: una, para el que llega con dinero, y otra para el que llega como nosotros". Pero la existencia de diferencias, de desigualdades, incluso de situaciones menesterosas, no justifica esa desordenada exhibición. Y es que también hay que proteger las opciones de los ciudadanos corrientes. Sin que sean de despreciar - aunque parezca un argumento frívolo ante tan delicado problema-, los motivos estéticos como antes decía, en beneficio de los propios ciudadanos que quieren lo mejor para su ciudad, pero contando también que se trata de ciudades en las que el turismo es una partida de enorme peso. 


\section{La prohibición de circular con la cara cubierta}

16. La fuerza de la libertad abre una enorme gama de posibilidades pero, a diferencia de lo que sucede en el sacrosanto espacio del domicilio, no ampara que en la calle se pueda ir vestido de cualquier manera o, incluso, desvestido. Ya para ir terminando, una tercera variante de tensión de derechos en la calle en relación con lo que se acaba de indicar. Cuando yo escribí mi trabajo que antes citaba sobre atuendos y vestimentas en la calle, estaba fresca la modificación de la Ordenanza de Civismo y Convivencia de Lérida, prohibiendo el uso del "velo integral" en el ámbito de los servicios municipales. Me refiero al velo integral, es decir, las distintas modalidades que tapan la cara manteniendo tan sólo los ojos descubiertos, con lo que dejo fuera obviamente cualquier variante de pañuelo o pañoleta que cubra tan sólo la cabeza $^{19}$. Al ser impugnada esa modificación de la Ordenanza, el Tribunal Superior de Justicia de Cataluña suspendió su aplicación como medida cautelar. Pero cuando corregí las pruebas del trabajo, el Tribunal había juzgado ya el fondo, y dio por buena la nueva medida. Pero continuó la impugnación, y el Tribunal Supremo la consideraría ilegal al no tener soporte en una ley, salvo lo referente al interior de los transportes públicos. Argumento de la legalidad al que antes me refería al hablar de las ordenanzas municipales. Supongo que a eso se debería el anuncio de que el Gobierno Catalán iba a proponer la promulgación de una ley que sirviera de soporte a ese tipo de medidas. Aunque dicha ley nunca apareció, no sé si es porque el Gobierno Catalán tiene algún problema más importante en que ocuparse que le absorbe toda su actividad, o porque se dudara de la competencia al respecto.

Pues bien, este tema es hoy de la mayor actualidad, debido a la reciente sentencia de la Gran Sala del Tribunal Europeo de Derechos Humanos, en el asunto "S.A.S. c. Francia", de uno de julio de 2014, referente a la Ley francesa de 11 de octubre de 2010. La Ley es rigurosa abordando con carácter general para todo el territorio francés una medida de algún modo similar a la referida, si bien se plantea de forma amplia sin personalizar específicamente los destinatarios. Según su artículo 1, "Nadie puede, en el espacio público, llevar una vestimenta destinada a ocultar la cara" 20 . Y se aclara que se entenderá como espacio público, según el artículo 2.1, las calles públicas y los lugares abiertos al público o afectados a un servicio público. La amplia fórmula del artículo 1 conoce, con todo, significativas excepciones, de forma

${ }^{19}$ Para una visión global del problema, me remito al capítulo noveno -"Los atuendos de significado religioso según la jurisprudencia del Tribunal Europeo de Derechos Humanos"- de mi libro, Estudios sobre libertad religiosa, Editorial Reus, Madrid 2011, 201 ss. Véase también mi trabajo, Los ayuntamientos y el régimen jurídico de atuendos y vestimentas, Una aproximación, cit. en nota 8.

${ }^{20}$ Según la versión original, "Nul ne peut, dans l'espace public, porter une tenue destinée à dissimuler son visage". 
que la prohibición no se aplica (artículo 2.2) en caso de que la vestimenta esté prescrita o autorizada por las leyes o reglamentos, si se justifica por razones de salud o por motivos profesionales, o si tiene lugar con motivo de prácticas deportivas o de fiestas y manifestaciones artísticas y tradicionales. Lo que implica que policías que encubren su cara, motoristas, jugadores de rugbi, y tantas otras actividades similares, incluyendo por supuesto los disfraces de carnaval, quedan excepcionados de la prohibición. El incumplimiento de la prohibición es objeto de sanción penal, si bien de escasa entidad: una multa de 150 euros como máximo y, eventualmente, acudir a un curso de ciudadanía.

La Ley tuvo un muy amplio respaldo en el Parlamento francés: la Asamblea Nacional la aprobó por 335 votos a favor, uno en contra y tres abstenciones, y el Senado, por 246 votos a favor y uno en contra. En el examen de constitucionalidad, el Consejo Constitucional le dio en principio el visto bueno, si bien, apoyándose en el artículo 10 de la Declaración de Derechos del Hombre y del Ciudadano de 1789, con su referencia a las libres opiniones religiosas, exigió que se interpretara ampliado el texto, en el sentido de que entre la excepciones a la prohibición se incluyeran también los lugares de culto ${ }^{21}$. Destaco esta utilización actual del viejo texto revolucionario, que como se sabe ha pasado a formar parte del bloque de la constitucionalidad.

La Ley, en su contenido, contiene una prescripción general con vocación totalizadora, de forma que en principio se aplicará a cualquiera que oculte su cara, pero se ha visto en ella una incidencia directa sobre las mujeres musulmanas que llevan el burka o el nikab. Al parecer, esta costumbre sería muy reciente en Francia -inexistente antes del año 2000-, y que afectaría a bien escasas mujeres, unas 1900 en el año 2009, de las cuales 270 en los territorios de Ultramar. Ese dato de la incidencia sobre las mujeres musulmanas suscitaría la enérgica enemiga de diversas organizaciones vinculadas a la defensa de los derechos humanos, que verían una discriminación por razón del sexo y también una violación de la libertad religiosa. Por su parte, se pronunciarían también contra la Ley la Asamblea Parlamentaria del Consejo de Europa así como el Comisario de Derechos del Hombre del propio Consejo de Europa, recalcando este último que una tal prohibición afectaría al respeto a la vida privada y a la identidad personal así como a las opciones de la libertad religiosa (artículos 8 y 9 del Convenio Europeo de Derechos Humanos). Desde otra perspectiva, hay que decir que por el momento, sólo dos países, Francia y Bélgica han introducido en su legislación dicha prohibición integral.

${ }^{21}$ En la argumentación del Consejo Constitucional se recuerda y reproduce también el artículo 4 de la Declaración de 1789, con su llamada a la consideración de los derechos de los demás, y que antes transcribía. 
17. El recurso ante el Tribunal Europeo de Derechos Humanos sería interpuesto por una mujer musulmana paquistaní residente en Francia, que prefiere ocultar su nombre bajo las tres letras que sirven para denominar el caso, que, aunque dice no llevar habitualmente el burka, desea poder hacerlo cuando le apetezca. Destaca expresamente que nadie le fuerza ni le obliga a llevar la vestimenta, con lo que quiere salir al paso de que sería una práctica degradante para las mujeres. De todas maneras, he de destacar que se trata de un recurso que ofrece algunas especialidades dignas de ser notadas. Porque no hubo ningún acto de aplicación concreta sobre S.A.S., es decir, no hay "víctima de una violación", en el sentido que parece exigir sin falta el artículo 34 del Convenio Europeo de Derechos Humanos ${ }^{22}$, por lo que, a simple vista, parece dificil que la demanda saliera adelante. El Tribunal, empero, parece estar decidido a conocer del caso y a resolverlo, sin que falte algún precedente en la jurisprudencia, como el del asunto "Dudgeon c. Irlanda del Norte", 22.X.1981. El argumento sería el de que está abierta una posible condena penal ${ }^{23}$. Con lo que a falta de una incidencia concreta de aplicación, el proceso se convierte en un puro análisis de la compatibilidad de la Ley francesa con el Convenio de Derechos Humanos metodología a la que por cierto habitualmente se opone el Tribunal Europeo ${ }^{24}$. Pero en el presente caso le debió parecer de interés al Tribunal resolver el asunto.

${ }^{22}$ Me remito a mi trabajo, El concepto "víctima de una violación de los derechos" como determinante para el acceso al Tribunal Europeo de Derechos Humanos, "Revista de Administración Pública", 175 (2008), 253 ss.

${ }^{23}$ En otro sentido, al margen de la amenaza penal, puede recordarse también, por sus especiales circunstancias, el asunto "Burden y Burden c. Reino Unido", 12.XII.2006, en el que el Tribunal no dudó en entrar el asunto aunque aparentemente fuera difícil acreditar que hubiera una "víctima de una violación". Lo he estudiado en el trabajo que cito en la nota anterior, páginas 281-282.

${ }^{24}$ Muy ilustrativas al respecto resultan dos decisiones de inadmisión similares, versando sobre el mismo problemas, los asuntos "Hafid OUARDIRI", Y "Liga de musulmanes de Suiza y otros", ambas contra Suiza, y las dos de 28 de junio de 2011. Se trata de un asunto curioso, y en gran medida escandaloso. A consecuencia de una iniciativa popular que obtuvo resultado favorable, a pesar de que tanto el Gobierno suizo (el Consejo Federal), como el Parlamento Federal Suizo, recomendaron que se votara en contra, se reformó la Constitución, añadiendo un precepto que decía: "Queda prohibida la construcción de minaretes" (artículo 72.3). Recurrieron al Tribunal Europeo, un ciudadano musulmán individualmente (francés, residente en Suiza, se dice), y varias organizaciones musulmanas. Al no haberse aportado pruebas de que los recurrentes puedan ser incluidos en la categoría "víctima de una violación", el Tribunal entiende que el recurso en puridad equivale a "una acción popular", a través de la cual se pretendería hacer controlar "en abstracto" la disposición constitucional discutida, confrontándola con el Convenio Europeo de Derechos Humanos, opción que no encaja, se recalca, en la regulación establecida. De ahí que se estime que hay una incompatibilidad "ratione personae" y se inadmita el recurso.

No deja de ser curioso pensar en el trasfondo de los dos asuntos, el de la prohibición de ocultar la cara y el de la prohibición de los minaretes. En el caso francés, el Tribunal admite el recurso y se decanta claramente para dar por bueno lo que tan mayoritariamente había aprobado 
Fueron admitidas en el proceso, a participar en concepto de terceros, cuatro organizaciones no gubernamentales, que se manifiestan todas contra la prohibición, insistiendo con energía en la libertad religiosa y en la libertad de expresión. Participó también el Gobierno belga, que obviamente se posiciona a favor de la prohibición, dado que en Bélgica existe una Ley similar. Destaca en su argumentación que el velo integral no responde a una prohibición del Corán sino a una costumbre minoritaria en la península arábiga. Con todo, señala, la Ley introduciría una prohibición general, aplicable a cualquiera, independientemente de que sea hombre o mujer.

Por su parte, la recurrente insiste en el respeto a la vida privada y a las prácticas culturales de las minorías. Quizá quepa entender así su argumento, que no deja de parecer sorprendente, de que habitualmente no usa el burka, pero que desea poder llevarlo sin problemas cuando le apetezca.

El Gobierno francés alega que hay fines legítimos que justifican y hacen necesaria la incidencia en la libertad que significa en definitiva la Ley. Hace hincapié sobre todo en dos razones. Ante todo, la defensa de la seguridad pública. Pero también, desde la perspectiva de la protección de los derechos de terceros, se pone énfasis en el respeto a un conjunto de valores de una sociedad democrática, entre los cuales la exigencia en la sociedad francesa de un "vivir juntos" ("vibre ensamble"). El ocultamiento del rostro sería contrario al ideal de fraternidad, y no satisface las exigencias mínimas de civismo en la relación social. Frente al respeto a la dignidad humana, ocultar el rostro representaría un considerarse borrado del espacio público, una evidente deshumanización.

La sentencia, muy elaborada - se recuerda incluso el caso de la ordenanza de Lérida y la correspondiente sentencia del Tribunal Supremo-, da por buena la Ley y no ve contradicción con las exigencias del Convenio Europeo de Derechos Humanos, en especial la libertad religiosa, la de expresión, el derecho a la intimidad o la no discriminación, en una votación que acarreó el resultado de 15 contra 2, en la que votaron en contra, y redactaron conjuntamente un voto disidente, dos de las mujeres jueces - Angelika Nussberger, de Alemania, y Helena Jäderblom, de Suecia-, si bien es cierto que no faltaron mujeres entre los jueces que votaron a favor.

el Parlamento francés. En el caso suizo, en cambio, el recurso no se admite, con lo que quedará intocada la reforma de la Constitución que había sido aprobada por la mayoría de ciudadanos y cantones.

He de decir, por otra parte, que las dos decisiones sobre el asunto suizo ofrecen muy interesantes razonamientos en relación con el concepto "víctima de una violación" que había estudiado con detenimiento en el trabajo que cité en la nota 22. 
Curiosamente, una especial manera de concebir "la protección de los derechos y libertades de los demás", jugaría como argumento decisivo en la fundamentación del Tribunal. No se acepta el argumento de la seguridad, dado que se presuponen los controles puntuales en los que obviamente la persona interesada tendrá que mostrar su rostro. En cambio, reconociendo un significativo margen de apreciación al Gobierno, y en ausencia de un consenso europeo sobre el tema, considera adecuado el fin de proteger la condición de vivir juntos como elemento propio de la protección de los derechos y libertades de terceros, algo que sería característico de la forma de vida en la República Francesa.

En mi opinión, el argumento de la seguridad pública tendría un peso razonable y convincente. Hoy la seguridad, en las complejas y entremezcladas sociedades de la era de la globalización, es una operación muy compleja que debe contar con bien variadas opciones y especialidades. Hay que reconocer sin duda el significado de los controles puntuales, pero creo que desempeñan también un papel muy importante las cámaras instaladas en los lugares adecuados para la protección pública. Es bien sabido lo útiles -y disuasorias- que resultan en autobuses, metros, comercios - señaladamente, bancos ${ }^{25}$, joyerías y supermercados-, en mi Facultad se instalaron a raíz de unos robos de ordenadores, pero también en calles y plazas, donde hay que proteger a los confiados turistas. En definitiva, entiendo que siempre que se manipulen con cuidado y con respeto a la intimidad ${ }^{26}$, son muy eficaces a la hora de disuadir o perseguir robos y hurtos cotidianos, pero también, como se ha demostrado, a la hora de dilucidar atentados terroristas. De todas maneras, la sentencia "S.A.S.", dando por buena la tan contundente toma de postura del Parlamento francés, resulta clara e inequívoca. En tal sentido, entiendo que no sería chocante que una prohibición similar se llevara aquí en España a algún texto de aplicación general - con la suficiente motivación en el preámbulo-, como la Ley de Seguridad Ciudadana, bien como inmediatamente vinculante, bien como soporte para que las ordenanzas municipales pudieran disponer al respecto.

${ }^{25}$ Vivo el recuerdo de aquel robo en banco que cometieron los patriotas de la eta un día de carnaval, protegidos por el correspondiente disfraz.

${ }^{26}$ Recuérdese especialmente la sentencia del propio Tribunal Europeo de Derechos Humanos "Peck c. Reino Unido", 28.IV.2003. Véase Xavier ARZOZ SANTISTEVAN, Videovigilancia, seguridad ciudadana y derechos fundamentales, Civitas, 2010. 


\section{A MODO DE GONGLUSIÓN}

18. Para concluir, a modo de recapitulación general, conviene recalcar la observación obvia de que la calle es un elemento decisivo en nuestra sociedad y en nuestro sistema de convivencia. De ahí el significado de que los instrumentos jurídicos vengan a ahormarla para que en ese espacio casi sagrado puedan desarrollarse con normalidad los tan importantes derechos fundamentales que en ella hallan el lugar de su expresión y desarrollo. Porque la calle es de propiedad municipal, es, de hecho, de todos y para todos. De ahí que haya que concienciar a los ciudadanos para que la respeten, dándole todo su valor sin abusar, muy presente la idea de que las opciones de los derechos fundamentales no son ilimitadas y de que resulta siempre decisiva la consideración del respeto a los derechos de los demás. Recordando que una sociedad democrática exige inexcusablemente unas pautas de comportamiento cívico en los ciudadanos: no todo es cuestión del Derecho, no todo habrá de resolverlo la policía. Aunque ciertamente, por lo mismo, que haya también que apremiar a las autoridades -y no es escasa la responsabilidad que corresponde a las municipales, pero no sólo a ellas-, para que la protejan y la defiendan sin cortapisas, tratando de contener los usos abusivos. Defender la ley, incluso prohibiendo y sancionando, no es ningún desdoro, es, en principio, defender a los ciudadanos indefensos a través del uso legítimo de los medios coactivos por parte de las autoridades, de ahí que sea una de las exigencias del Estado de Derecho. 